\title{
Labour Market Dynamics in Greek Regions: a Bayesian Markov Chain Approach Using Proportions Data
}

\author{
GEORGE A. CHRISTODOULAKIS \\ Manchester Business School, University of Manchester \\ EMMANUEL C. MAMATZAKIS \\ University of Piraeus ${ }^{*}$
}

\begin{abstract}
This paper focuses on Greek labour market dynamics at a regional base, which comprises of 16 provinces, as defined by NUTS levels 1 and 2 (Eurostat, 2008), using Markov Chains for proportions data for the first time in the literature. We apply a Bayesian approach, which employs a Monte Carlo Integration procedure that uncovers the entire empirical posterior distribution of transition probabilities from full employment to part employment, unemployment and economically unregistered unemployment and vice a versa. Our results show that there are disparities in the transition probabilities across regions, implying that the convergence of the Greek labour market at a regional base is far from being considered as completed. However, some common patterns are observed as regions in the south of the country exhibit similar transition probabilities between different states of the labour market.
\end{abstract}

Keywords: Greek Regions, Employment, Unemployment, Markov Chains

JEL Classifications: C53, E24, E27, E37

\section{Introduction}

Based on a recent report of Eurostat (2008), levels of regional disparities in employment and unemployment have been narrowing over the last five years in the EU. However, notwithstanding these general labour market improvements, almost $20 \%$ of the EU-27 active population is still living in underperforming regions as regards unemployment. Moreover, in the case of Greece Eurostat (2008)_ argues that the regional employment rate exhibits no sign of convergence with the dispersion remaining high, whereas the dispersion of unemployment

\footnotetext{
* We would like to thank participants of the "Geographical Localisation, Intersectoral Reallocation of Labour and Unemployment Differentials” workshop of the Rimini Centre of Economic Analysis. We would also like to thank an anonymous Referee for constructive comments on an earlier version of the paper. Special thanks to G. Pelloni for originally proposing the idea to examine labour market dynamics at a regional base. Thanks also to T. Panagiotidis and D. Dorling.

(C) 2009 George A. Christodoulakis and Emmanuel C. Mamatzakis. Licensed under the Creative Commons Attribution - Noncommercial Licence 3.0. Available at http: / / rofea . org .
} 


\section{CHRISTODOULAKIS AND MAMATZAKIS Unemployment in Greek Regions}

rate being somewhat lower. ${ }^{1}$ EU Commission (2008) also highlights that the reduction of regional inequalities in the labour market and particularly the reduction of differences in employment and unemployment rates among regions is of primal importance for enhancing social cohesion and limiting the danger of social exclusion.

At an aggregate level, the situation in the Greek labour market is improving, but at a very slow pace. The employment growth is not satisfactory and unemployment, although it fell below $8.5 \%$ of the labour force in 2007, remains at a high level. Moreover, unemployment fell for a seventh consecutive year in 2007, whereas it remains well above the EU average with the unemployment rate for women being more than double the rate for men, and the unemployment rate of youth remaining very high. On the other hand, Greece's overall employment rate at $49 \%$ in 2007 undershoots by big distance the target of $70 \%$ overall employment rate by 2010 set by the European Council in Lisbon in 2000, and also the target for women employment rate of $60 \%$ or over by 2010. There many causes of this underperformance of the Greek labour market. Most part of this underperformance is caused by labour-market rigidities that hamper a more flexible functioning of the labour market (see EU Commission, 2008). Also, there have been no changes in the wage formation system that would allow greater differentiation according to productivity and skills. The remaining complexity of the tax system, despite some improvements over the years, the high social security contributions and the stringent employment protection legislation are still important obstacles to hiring. Moreover, the limited impact of reforms aimed to promote flexible forms of employment point to the fact that many employers have recoursed to adopt flexibility practices through the informal economy. The reform of the public employment services, which is essential to address the high level of long-term unemployment, is still pending. In addition, the interplay of rigidities in labour and product markets and the late development of knowledge based society, due to the low level of investment in human capital and in research, are impeding the increase in labour productivity to levels that would accelerate the catchingup process with the EU average and boost employment rates.

This paper does not convey the ambition to address all causes related to the sluggish performance of Greek labour market; we rather focus on an issue that has not been investigated, to our knowledge, in the literature. Moreover, we focus on the labour market dynamics at a regional level in Greece. The case of Greece is of particular interest due to specific idiosyncratic characteristics such as the very low professional and geographic mobility (EU Commission, 2008). As a result, marked regional inequalities emerge that, in turn, lead to high disparities in the employment and unemployment rates across regions (National Action Plan for Employment, 2008). It is, therefore, of interest to examine the exact

\footnotetext{
${ }^{1}$ The dispersion of unemployment rates is expressed by the coefficient of variation of regional unemployment rates.
} 
labour market dynamics across Greek regions.

In the literature, several studies have focused on labour market dynamics, building upon the work of Mortensen and Pissarides (1994), which examines the dynamics between unemployment and employment. Gali (1999) using a structural vector autoregression (SVAR) argues that the dynamics in employment could be explained by the shocks in technology and labour productivity. Yet, the literature on labour market dynamics is not conclusive. Christiano et al. (2004) criticise the findings of Gali (1999).

Regarding regional unemployment rates, Elhorst (2003) in a comprehensive survey reports the underlying driving forces of regional unemployment. Moreover, he argues that regional unemployment rate is mainly a function of the labor force participation rate and the employment growth rate at regional level. Blanchard and Katz (1992) were the first to propose to examine the unemployment rate, the participation rate and the employment growth within the same framework, arguing that over the business cycle the employment growth would eventually converge to steady state but the level of employment would differ depending of the magnitude and sign of the labour shock in the short run. The short run changes in the employment growth would affect unemployment and participation and if regional wages are flexible would also change real wage. On the other hand, Decressin and Fatás (1995) suggest that short run fluctuations in unemployment in the EU are mostly explained by the number of people moving in and out of the labour force.

With reference to the order of integration, most studies (see Blanchard and Katz, 1992; Martin, 1997; Baddeley et al., 1998) argue that the unemployment rate and the participation rate at regional level are integrated of order 0 , whereas the level of employment could be integrated of order 1 (Decressin and Fatás, 1995).

Although, this literature attempts to identify the underlying factors, such as productivity shocks, employment growth, participation rate and factors related to the business cycle, that influence mainly employment dynamics, an issue that has not been investigated and remains open concerns the magnitude of the transition probability between different states of labour market. In this paper, we depart from the analysis of the above studies and employ instead Markov Chains analysis using proportions data, for the first time in the literature, to address the issue of the underlying labour market dynamics for Greek regions.

In detail, we adopt a Bayesian approach so as to estimate the transition probabilities between four different states, namely full time employment, part employment, unemployment and lastly economically inactivity population. Our contribution is, thus, twofold: first, we study the dynamics of four different states of labour market using a Markov process for proportion data at a regional basis. To the best of our knowledge a similar investigation for Greek regions is lacking in the literature. Second, in the empirical analysis we employ a Bayesian estimation method through Monte Carlo Integration that uncovers the entire empirical posterior distribution for each probability estimate of the transition matrix. 


\section{CHRISTODOULAKIS AND MAMATZAKIS Unemployment in Greek Regions}

In what follows, section 2 presents some stylized facts for the Greek labour market, section 3 reports the methodological framework. Section 4 presents the empirical results, while section 5 concludes.

\section{Stylised Facts}

Overall, the employment rate of the Greek economy demonstrates a slight upward trend in recent years. Starting from $46 \%$ in 1999 , the employment rate increased to $49 \%$ in 2007 . An improvement in the female employment rate has also been recorded, up from $45.2 \%$ in 2004 to $47.9 \%$ in 2007 and $49.0 \%$ in the second quarter of 2008. Despite this improvement, employment rate in Greece remains well below the EU average. Moreover, the gap between female and male employment rates persists. The employment rate for young persons (15-24 years) is extremely low at $24 \%$ in 2007 , whereas the employment rate of older workers (55-64 years) also lags at $42.4 \%$ in 2007.

In terms of regional employment rates, Diagram 1 depicts a picture that demonstrates that to some extend some common pattern across regions might exist, though disparities are not absent. The highest employment rate in 2007 is recorded in Attiki at 51.2\%, a significant rise from $45.4 \%$ in 1999. High employment rates are also observed in recent years in Peloponnesus and Aegean Islands at 50.2\% and 50.9\% in 2007 respectively. The remaining regions demonstrate some moderate improvement over the years, notably in the case of Thessaly. Employment rate developments are not at all favourable in Ionian Islands, where the rate fell to $46.5 \%$ in 2007 down from 50.7\% in 1999 to. Also, note that the rate of West Greece, though it performs better than Sterea early in the sample, deteriorates in recent years, taking the lowest value across all regions of $45.6 \%$ in 2007.

Regarding developments in unemployment, the decline in the unemployment rate and the number of unemployed workers alike should be noted, though at the rate of $8.3 \%$ in 2007 it is well above the average of the Euro-area of $7.2 \% .2$ According to the National Statistical Service of Greece (NSSG), the unemployment rate decreased from 12.1\% in 1999 to 8.3\% in 2007 and, according to the latest available data, remained on this downward trend in 2008. In terms of sex, the unemployment rate for male workers in 2007 stood below the EU-27

\footnotetext{
${ }^{2}$ In order to be entitled to unemployment benefit in Greece you need to have paid social contributions for two consecutive years. For the first-time unemployed the insured must have at least 80 working days in the last two years. For subsequent claims the insured must have at least 100 working days in the last 12 months. These strict criteria leave quite a lot of people to be accounted as economically unregistered unemployed, when indeed they could seek for employment. The rate of economically unregistered unemployment has always been quite substantial in Greece remaining above $3.5 \%$ in the eighties and the nineties, though over recent years it is falling, reaching $2 \%$ in 2007. The high rate of economically unregistered unemployment necessitates a closer look at its underlying dynamics. It is for this reason that the transition probability matrix also accounts for the state of economically unregistered unemployment.
} 
average at 5.2\%. However, the female unemployment rate remained above the EU-27 average, despite declining to $12.8 \%$ in 2007 . Recent available data for the second quarter of 2008 indicate a decrease in the male unemployment rate to $4.7 \%$ along with a significant drop in the female unemployment rate to $10.9 \%$. Sadly, the encouraging signs of early 2008 have since disappeared as the economy has entered in a period of high risks and severe economic downturn.

\section{Diagram 1: Employment Rates in Greek Regions in 2007}

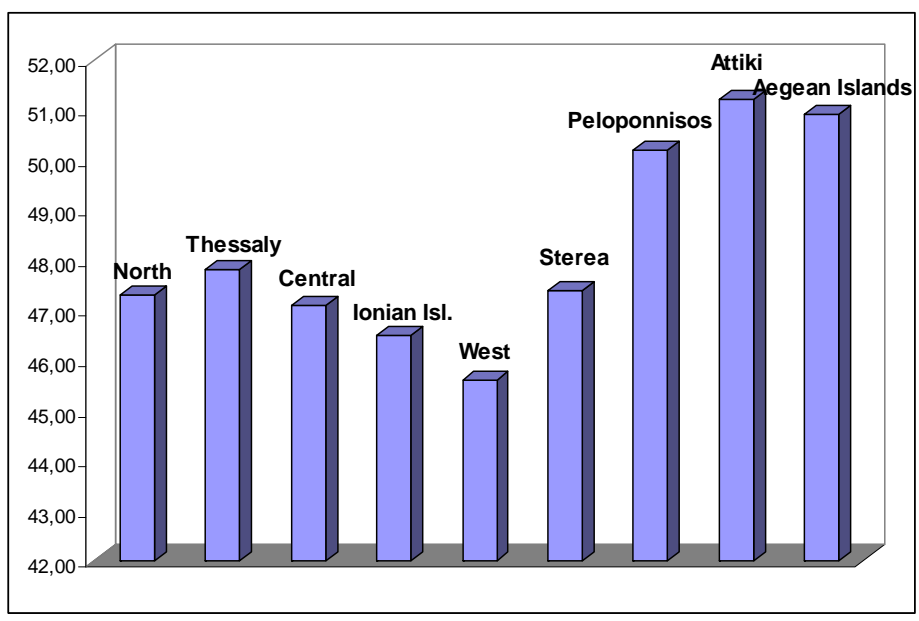

Source: Eurostat, Regional Employment Data.

Across regions (see Diagram 2), we observe high unemployment rates, whilst there disparities across regions. Aegean Islands, Attiki and Peloponnesus consistently have the lowest rates, at 6.7\%, 7.6\%, and 7.5\% in 2007 respectively. A pleasant surprise comes from Thessaly that marks substantial improvement from $13.4 \%$ in 1999 to $7.8 \%$ in 2007. Again here, the worst performer is the West of Greece with a rate of $9.6 \%$ in 2007 , though it declines from $11.7 \%$ in 1999.

A close inspection of the above employment and unemployment Diagrams by region highlights disparities across regions as there is an apparent lack of harmonisation. Moreover, despite some common patterns in movements of employment and unemployment rates across regions, we observe marked differences that could be the outcome of diverging region specific market dynamics. Also if one considers that the relatively favourable labour market outlook is now behind us, a number of serious concerns arise regarding the exact nature of the regional markets' underlying dynamics.

This paper bridges a gap in the literature by providing evidence of the regional dynamics and identifying the exact transition patterns between different states of labour market. This 


\section{CHRISTODOULAKIS AND MAMATZAKIS Unemployment in Greek Regions}

identification would assist attempts to improve policy by prioritising actions to those particular states of labour market that exhibit stronger persistence, aiming at increasing employment rates and at decreasing unemployment. For example, by observing the transition probabilities from employment to unemployment and vice a versa for each Greek region we would be able to identify labour market policies that could, in turn, shorten the transitionperiod between unemployment and employment.

Diagram 2: Unemployment rates in Greek Regions in 2007.

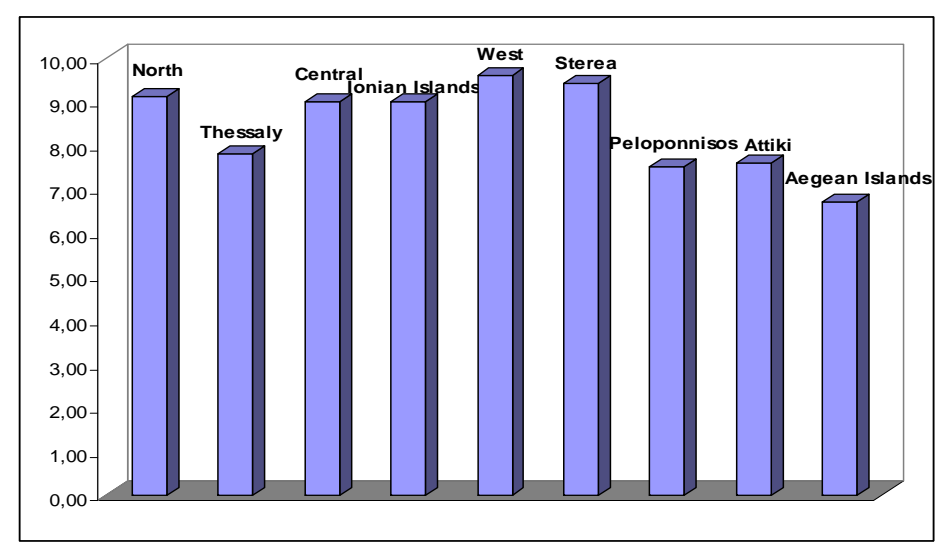

Source: Eurostat, Regional Employment Data.

\section{Bayesian Estimation for Markovian Transition Probabilities}

Policy makers often work with aggregate data to monitor the evolution of central tendencies of key policy variables. In this context we shall assume that the researcher observes only the aggregate proportions relating to the decomposition of the full work force into four classes at every time t: Full-Time employment (FT), Part-Time employment (PT), Unemployment (UN) and unregistered unemployment (UU). Following Jones (2005) we denote the probability of the joint event that a worker zt falls in two different employment states, si and sj, in two sequential periods, $\mathrm{t}-1$ and $\mathrm{t}$, as

$$
\operatorname{Pr}\left(z_{t}=s_{j}, z_{t-1}=s_{i}\right)=\operatorname{Pr}\left(z_{t-1}=s_{i}\right) \operatorname{Pr}\left(z_{t}=s_{j} \mid z_{t-1}=s_{i}\right)
$$

Substituting recursively we obtain

$$
\operatorname{Pr}\left(z_{t}=s_{j}\right)=\sum_{i} \operatorname{Pr}\left(z_{t-1}=s_{i}\right) \operatorname{Pr}\left(z_{t}=s_{j} \mid z_{t-1}=s_{i}\right)
$$

The state, $s_{i}$ takes the form of four mutually exclusive employment states as described above. In this analysis, the observable elements are the unconditional probabilities in the above equation, which are in the form of aggregate proportions in each employment state. 
Then, we are interested in estimating the conditional transition probabilities between employment states, which form the time homogeneous transition probability matrix $P$.

$$
P=\left[\begin{array}{llll}
p_{F T, F T} & p_{F T, P R} & p_{F T, U N} & p_{F T, U U} \\
p_{P T, F T} & p_{P T, P T} & p_{P T, U N} & p_{P T, U U} \\
p_{U N, F T} & p_{U N, P T} & p_{U N, U N} & p_{U N, U U} \\
p_{U U, F T} & p_{U U, P T} & p_{U U, U N} & p_{U U, U U}
\end{array}\right]
$$

The transition matrix, $P$, is a Stochastic Matrix which represents a stochastic process only if it is associated to a converging generator matrix $G$. This is ensured if and only if $P$ is diagonal dominant, which requires that all elements in the main diagonal exceed 0.5. Thus, the empirical implementation of the transition matrix $P$ is subject to the above constraint, as well as that each row sums to unit and all matrix elements are non-negative.

Equation (2) can now be transformed into an empirical model of the form

$$
x_{j, t}=\sum_{i} x_{i, t-1} P_{i j}+u_{j, t}
$$

by substituting the unconditional probabilities with observed aggregate proportions $x_{j}$ and adding a random error term $u_{j}$, whilst the conditional transition probabilities $P_{i j}$ are left as unknown parameters. For a finite sample of $T$ data points, our constrained model can be written compactly as:

$$
X_{j}=Z_{j} P_{j}+u_{j} \text { s.t. } l^{\prime} P_{j}=1, P_{j} \geq 0, P_{j i}>0.5 \text { for } j=I
$$

where $X$ is a vector of $T$ observations, $Z$ a matrix of $T$ observations for $K$ employment states, $P$ a vector of $K$ conditional transition probabilities, $\mathbf{1}$ is a vector of units and $\boldsymbol{u} \sim N\left(0, \sigma^{2} I\right)$. We impose the equality constraint by restating the model in deviations from the $k$-th employment state proportion, where the $t$-th elements of the new variables are now denoted as $x_{t}^{*}=x_{t}-z_{k, t}$ and $z_{i, t}^{*}=z_{i, t-1}-z_{k, t-1}$, where $i=1, \ldots, K-1$ is the $i$-th column of $X$. Now the transition probability vector $P^{*}$ has $K$-1 elements whilst the $K$-th $P$ can be obtained from the "sum to unity" constraint $1-\mathbf{1}^{\prime} P^{*}$. As a standard assumption, all elements of $Z^{*}$ are independent of each other and of $u, \mathrm{P}^{*}$ and $\sigma^{2}$.

Applying Bayes law, the joint posterior density of $P^{*}$ and $\sigma^{2}$ is given as:

$$
\text { Posterior }\left(P^{*}, \sigma^{2} \mid x^{*}, Z^{*}\right)=\operatorname{Likelihood}\left(P^{*}, \sigma^{2} \mid x^{*}, Z^{*}\right) \times \operatorname{Prior}\left(P^{*}, \sigma^{2}\right)
$$

where we have dropped the subscript $j$ for employment state. 


\section{CHRISTODOULAKIS AND MAMATZAKIS Unemployment in Greek Regions}

Details regarding the Bayesian empirical estimation ${ }^{3}$ under linear constraints using Monte Carlo integration are reported in Appendix in line with Geweke (1986).

\section{The Data and the Empirical Results}

The data for the empirical analysis come from Eurostat's regional statistics, regional employment and unemployment at NUTS levels 1 and 2 and concern 16 Greek regions, namely: East Makedonia and Thraki (East MAK \& T), Central Makedonia (Central MAK), West Makedonia (West MAK), Thessaly, Ipeiros, Ionian Islands, Sterea, Attiki, Peloponnesus, North Aegean, South Aegean, Crete. Our labour data includes full-time employment, part employment, unemployment and economically unregistered unemployment from 1983 to 2007.

In the present analysis the variables of our interest, that is full time employment, part employment, unemployment and economically unregistered unemployment, are taken as proportions of total economically active population. These proportions are then represented in changes so as to be able to estimate the underlying distribution dynamics from one state of labour market to another, referring to an evolving cross-sectional distribution over time and its persistence and transition characteristics.

Table 1 shows the transition probability matrix for the four states of labour market. In detail, the elements in the main diagonal of Table 1 provide information about persistence, as they represent estimates of non-transition probabilities, the likelihood of staying in the same state next period. According to the results, there is above 80 percent probability that an employee remains in full time employment next year in all regions but in Peloponnesus, while Crete is just above $80 \%$. This result could imply that full time employment persistence in all regions is quite high, whilst higher degree of flexibility towards other form of employment or unemployment is observed only for two regions, namely Peloponnesus and Crete. It is not by coincidence that those regions are exhibiting, together with Attiki, the highest employment rates across Greek regions. Given the high persistence of full employment comes as no surprise that part time employment's persistence is much lower for all regions, around 60 percent. In addition, lower persistence is observed in the case of unemployment and unregistered unemployment that takes values of around 60 percent or lower for most regions. It is of interest the region of Crete, which reports a high persistence of unemployment at 66

\footnotetext{
${ }^{3}$ It is worth noting, as proposed by the Referee, that since the constraints are linear we could use Gibbs sampler in the empirical estimation of Equation (6) (see Geweke, 1996). The main advantage of the Gibbs sampler is it simplicity as it considers univariate conditional distributions or simple multivariate conditional distributions (that is the case of a distribution when the remaining random variables are assigned fixed values), and thereby such conditional distributions are easier to simulate than complex joint distribution. For the purpose of the current paper, following van Dijk and Kloek (1980) we opt for using joint distributions given that the posterior density is well defined (see Equation 6) and our data set is expanded over three decades.
} 
Review of Economic Analysis 2 (2010) 32-45

percent compared to the other regions. One could interpret this result in the following way; the high employment rate and the low unemployment rate in Crete, compared to most regions in Greece, comes at the cost of higher persistence in unemployment. Unemployed in Crete remain at this state with a higher probability compared to other regions. The reported high persistent in unemployment provides evidence of the existence of a possible unemployment trap in Crete. This adverse finding comes in sharp contrast to the low unemployment rates of the island.

Table1. The One-Step Transition Probability Matrix

\begin{tabular}{|c|c|c|c|c|}
\hline East MAK\&T & FT & PT & UN & UU \\
\hline FT & 0.841 & 0.0387 & 0.0216 & 0.0986 \\
\hline PT & 0.1758 & 0.6076 & 0.1169 & 0.0997 \\
\hline UN & 0.1664 & 0.1072 & 0.6274 & 0.099 \\
\hline UU & 0.1316 & 0.108 & 0.1627 & 0.5978 \\
\hline Central MAK & FT & PT & UN & UU \\
\hline FT & 0.8749 & 0.0281 & 0.0414 & 0.0556 \\
\hline PT & 0.181 & 0.6111 & 0.0933 & 0.1146 \\
\hline UN & 0.1388 & 0.1696 & 0.598 & 0.0936 \\
\hline UU & 0.1468 & 0.1069 & 0.1423 & 0.6041 \\
\hline West MAK & FT & PT & UN & UU \\
\hline FT & 0.8481 & 0.0309 & 0.065 & 0.056 \\
\hline $\mathrm{PT}$ & 0.168 & 0.5951 & 0.1072 & 0.1297 \\
\hline UN & 0.1509 & 0.1468 & 0.5995 & 0.1029 \\
\hline UU & 0.1552 & 0.1226 & 0.1205 & 0.6017 \\
\hline Ipeiros & FT & PT & UN & UU \\
\hline FT & 0.8464 & 0.0741 & 0.0544 & 0.0252 \\
\hline PT & 0.1888 & 0.6132 & 0.1253 & 0.0727 \\
\hline UN & 0.1636 & 0.1365 & 0.6084 & 0.0916 \\
\hline UU & 0.1533 & 0.1024 & 0.0884 & 0.6559 \\
\hline Thessaly & FT & PT & UN & UU \\
\hline FT & 0.8714 & 0.0313 & 0.0581 & 0.0392 \\
\hline PT & 0.1297 & 0.6532 & 0.1508 & 0.0663 \\
\hline UN & 0.1925 & 0.0497 & 0.6078 & 0.1501 \\
\hline UU & 0.1495 & 0.0827 & 0.1631 & 0.6047 \\
\hline Ioanian Islands & FT & PT & UN & UU \\
\hline FT & 0.9172 & 0.0303 & 0.0302 & 0.0223 \\
\hline PT & 0.0905 & 0.579 & 0.1243 & 0.2063 \\
\hline UN & 0.1177 & 0.1315 & 0.5911 & 0.1597 \\
\hline UU & 0.1628 & 0.1201 & 0.0899 & 0.6271 \\
\hline Sterea & FT & PT & UN & UU \\
\hline FT & 0.8654 & 0.0395 & 0.0386 & 0.0565 \\
\hline $\mathrm{PT}$ & 0.1495 & 0.6408 & 0.1387 & 0.0711 \\
\hline UN & 0.1664 & 0.0829 & 0.6113 & 0.1394 \\
\hline UU & 0.1547 & 0.1074 & 0.1355 & 0.6025 \\
\hline
\end{tabular}


CHRISTODOULAKIS AND MAMATZAKIS Unemployment in Greek Regions

\begin{tabular}{|c|c|c|c|c|}
\hline Attiki & FT & PT & UN & UU \\
\hline FT & 0.8731 & 0.0351 & 0.0429 & 0.0489 \\
PT & 0.1665 & 0.6336 & 0.1141 & 0.0859 \\
UN & 0.2009 & 0.0832 & 0.6236 & 0.0923 \\
UU & 0.2148 & 0.0909 & 0.0695 & 0.6248 \\
\hline Peloponnesus & FT & PT & UN & UU \\
\hline FT & 0.746 & 0.1402 & 0.0609 & 0.0529 \\
PT & 0.1579 & 0.6199 & 0.0932 & 0.1289 \\
UN & 0.1072 & 0.0985 & 0.5876 & 0.2067 \\
UU & 0.2197 & 0.0849 & 0.0698 & 0.6257 \\
\hline North Aegean & FT & PT & UN & UU \\
\hline FT & 0.8128 & 0.0951 & 0.0567 & 0.0354 \\
PT & 0.1366 & 0.6048 & 0.0901 & 0.1685 \\
UN & 0.1546 & 0.1142 & 0.617 & 0.1142 \\
UU & 0.1523 & 0.119 & 0.1247 & 0.6041 \\
\hline South Aegeon & FT & PT & UN & UU \\
\hline FT & 0.8642 & 0.0576 & 0.021 & 0.0572 \\
PT & 0.1468 & 0.6088 & 0.1142 & 0.1302 \\
UN & 0.1682 & 0.1009 & 0.6352 & 0.0957 \\
UU & 0.1235 & 0.1132 & 0.1602 & 0.6031 \\
\hline FT & FT & PT & UN & UU \\
\hline PT & 0.8074 & 0.1524 & 0.0154 & 0.0248 \\
UN & 0.172 & 0.6205 & 0.1116 & 0.0959 \\
UU & 0.1256 & 0.1052 & 0.6602 & 0.109 \\
& 0.0956 & 0.1574 & 0.1484 & 0.5986 \\
\hline
\end{tabular}

Source: Authors' Estimations.

Note: $F T=$ full time employment, $P T=$ part time employment, $U N=$ unemployment, $U U=$ unregistered unemployment.

Now, in terms of off diagonal transition probability, the upper diagonal of probabilities reports transition to a worst state, i.e. from full time employment to part time and so on, whilst the lower diagonal reports transition to a better off state. The off diagonal matrix elements in Table are quite substantial in magnitude in the case of transition from the state of unemployment to unregistered unemployment in the region of West Makedonia and Thraki, reporting a probability close to 10 percent, whereas in regions of Central and West Makedonia at 11 percent and 13 percent respectively. This result is worth to note in conjecture that the fact that those regions have the lowest level of employment rate and highest rate of unemployment in Greece.

In addition, the high transition probabilities from part time to unregistered unemployment could signify one of the rigidities of Greek labour market at an institutional level. Given that in order to receive unemployment benefit in Greece an individual needs to be insured for not less than eighty days, those part-time employees that fall short end up outside the labour market without any assistance, aggravating poverty. 
In the case of transition probability from unemployment to full time, Attiki at 20 percent exhibit the highest value across regions. The remaining regions report significant lower values, ranging from 10 percent to slightly above 16.5 percent.

Finally, the transition probability from unregistered unemployment to unemployment is higher again in the case of Attiki at 21 percent, but also in the region of Peloponnesus at 22 percent. The rest take values from close to 10 percent in the case of Crete to 16.2 percent in the region of Ionian Islands.

The above reported transition probabilities appear to explain why some certain regions such as Crete, South Aegean and Peloponnesus have been consistently experiencing high employment, and low levels of unemployment, and appear to be most able to meet the demands of changing labour market conditions.

Overall, the results pinpoint that there are disparities in the transition probabilities across regions, implying that the regional labour market convergence in Greece is far from being considered as completed. It also becomes apparent that regions with high employment rates and low unemployment rates report high employment and unemployment persistence, i.e. Crete.

These results comes in agreement with previous evidence in the literature (for a survey see Elhorst, 2003). Moreover, Elhorst (2003) building on Blanchard and Katz (1992) argues that the main underlying driving force of regional unemployment is the employment rate together with the participation rate at regional level.

In terms of economic policy, the identification of the underlying labour market dynamics is useful for economic policy as they highlight an ongoing slow process of convergence across regions, thereby suggesting that efforts, aiming at boosting employment and thus lowering unemployment, should be enhanced so as to alleviate social inequalities and combat regional poverty.

\section{Conclusion}

This paper focuses on the evolution of some key states of labour market at a regional base in Greece. We model the evolution of labour market states using Markov Chains for proportions of aggregate data. This approach uncovers the entire empirical posterior distribution of transition probabilities from employment to part employment, temporary employment and unemployment respectively, for which statistical inferences are readily available.

The results reveal marked disparities between regions. Some common patterns, however, are also present. The estimation of transition probabilities shows that a slow ongoing process of convergence in the Greek labour market is underway, especially for the regions located in the south of the country.

In terms of economic policy, improving work incentives, particularly by reducing nonwage costs and improving transferability of pension's rights, could raise employment rate in 


\section{CHRISTODOULAKIS AND MAMATZAKIS Unemployment in Greek Regions}

the formal sector and thus raise persistence for full time employment, including part time work. Along these lines, reform efforts are particularly welcome in the area of the wage bargaining process so as to ensure that wages reflect productivity differentials. Moreover, and in line with EU Commission's (2008) assessment, Greece should implement a comprehensive structural reform in labour market so as to improve the balance between flexibility and security by reviewing excessively restrictive labour-market regulations.

\section{References}

Baddeley, M., R. Martin and P. Tyler (1998), Transitory Shock or Structural Shift? The Impact of the Early 1980s Recession on British Regional Unemployment, Applied Economics, 30, 19-30.

Blanchard, O.J. and L.F. Katz (1992), Regional Evolutions, Brookings Papers on Economic Activity, no. 1, 1-75.

Christiano, L., M. Eichenbaum and R. Vigfusson (2004), The Response of Hours to a Technology Shock: Evidence Based on Direct Measures of Technology, Journal of the European Economic Association, 2 (May), pp. 381-395.

Christodoulakis, G. A. (2007), Markovian Credit Transition Probabilities under Inequality Constraints: the US Portfolio 1984-2004, Journal of Credit Risk, Vol. 3, 25-39,

Decressin, J. and A. Fatás (1995), Regional Labor Marker Dynamics in Europe, European Economic Review, 39, 1627-1655.

Elhorst, J.P. (2003), The Mystery of Regional Unemployment Differentials: Theoretical and Empirical Explanations, Journal of Economic Surveys 17, 709-748.

EU Commission, (2008), The Commission Draft of the Joint Employment Report, Brussels.

EU Commission, (2005), The Commission Draft of the Joint Employment Report, Brussels.

Eurostat (2008), General and Regional Statistics, Regional Labour Market Disparities are Narrowing, Statistics in Focus, 84, Luxemburg.

Eurostat (2008), Europe in Figures, Eurostat Yearbook and other compendiums, Luxemburg.

Gali, J. (1999), Technology, Employment, and the Business Cycle: Do Technology Shocks Explain Aggregate Fluctuations, American Economic Review, 89(1), 249-71.

Geweke, J., (1986), Exact Inference in the Inequality Constrained Normal Linear Regression Model, Journal of Applied Econometrics, 1, 127-141.

Geweke, J., (1996), Bayesian Inference for Linear Models Subject to Linear Inequality Constraints, In A. Zellner and J.S. Lee. eds. Modeling and Prediction: Honoring Seymour Geisser. New York, Springer.

Kloek, T. and H. K. van Dijk (1978), Bayesian Estimates of Equation System Parameters: an Application of Integration by Monte Carlo, Econometrica, 46, 1, 1-19.

Martin, R. (1997), Regional Unemployment Disparities and their Dynamics, Regional Studies 31, 237-252. 
Mortensen, D. and C. A. Pissarides (1994), Job Creation and Job Destruction in the Theory of Unemployment, Review of Economic Studies 61, 3, 397-415.

MNEC 2008, National Action Plan for Employment, Ministry of Economy and Finance. van Dijk, H. K. and T. Kloek (1980) Further Experience in Bayesian Analysis Using Monte Carlo Integration, Journal of Econometrics, 14, 307-328

\section{APPENDIX}

The empirical implementation of Equation (6) requires simulation in finite samples. Following van Dijk and Kloek (1980) the prior in Equation (6) is composed of an uninformative component for $\sigma^{2}$ and an informative one for $P^{*}$. Note that by independence: Prior $\left(\boldsymbol{P}^{*}, \sigma^{2}\right)=\sigma^{-1} q\left(\boldsymbol{P}^{*}\right)$, where $q\left(\boldsymbol{P}^{*}\right)=1$ if $\mathbf{1}^{\prime} \boldsymbol{P}^{*} \leq 1$ and $\boldsymbol{P}^{*} \geq 0, \quad 0$ otherwise. Then, under multivariate normality for $u$ and integrating out $\sigma$ using standard analysis, the marginal posterior probability density for $\boldsymbol{P}^{*}$ is:

$$
\operatorname{Post.}\left(P^{*} \mid x^{*}, Z^{*}\right)=c\left[\lambda+\frac{\left(P^{*}-b\right)^{\prime} Z^{\prime^{*}} Z^{*}\left(P^{*}-b\right)}{\hat{\sigma}^{2}}\right]^{-\frac{1}{2}(\lambda+K-1)} \times q\left(P^{*}\right)
$$

where Post. denotes Posterior, $c=\frac{\lambda^{\frac{\lambda}{2}} \Gamma\left[\frac{1}{2}(\lambda+K-1)\right]}{\pi^{\frac{K-1}{2}} \Gamma\left[\frac{\lambda}{2}\right] \operatorname{det}\left(\hat{\sigma}^{2}\left(Z^{\prime^{*}} Z^{*}\right)^{-1}\right)^{\frac{1}{2}}}$ and $\Gamma($.$) is the$ gamma function. This is a multivariate $t$ density with mean zero, variance $\frac{\lambda}{(\lambda-2) \hat{\sigma}^{2}} Z^{\prime^{*}} Z^{*}$ and $\lambda=v$ degrees of freedom.

We follow the methodology proposed by van Dijk and Kloek (1980), who show that for any function $g($.$) , the point estimator of g\left(\boldsymbol{P}^{*}\right)$ is given by:

$$
E\left(g\left(P^{*}\right) \mid x^{*} Z^{*}\right)=\frac{\int g\left(P_{i}^{*}\right) \text { Post } .\left(P^{*} \mid x^{*} Z^{*}\right) d P^{*}}{\int \text { Post. }\left(P^{*} \mid x^{*} Z^{*}\right) d P^{*}}
$$

For the numerical implementation of (A2) using Monte Carlo procedures under (linear) constraints as described in Geweke (1986), we use an importance function $I\left(\boldsymbol{P}^{*}\right)$, as a proxy 


\section{CHRISTODOULAKIS AND MAMATZAKIS Unemployment in Greek Regions}

to Equation (6), from which random draws of $\boldsymbol{P}^{*}$ will be taken. Let $\boldsymbol{P}_{1}^{*}, \boldsymbol{P}_{2}^{*}, \ldots, \boldsymbol{P}_{N}^{*}$ be a set of $N$ random draws from $I\left(\boldsymbol{P}^{*}\right)$, then it can be shown that:

$$
\lim _{N \rightarrow \infty} \frac{1}{N} \sum_{i=1}^{N} \frac{g\left(P_{i}^{*}\right) \text { Post. }\left(P_{i}^{*} \mid x^{*} Z^{*}\right)}{I\left(P_{i}^{*}\right)}=E\left(g\left(P^{*}\right) \mid x^{*} Z^{*}\right)
$$

The normalizing constant can be calculated separately. Since $I\left(\beta^{*}\right)$ is supposed to be a proxy to the posterior distribution, Equation (6) suggests that we should choose the multivariate $t$ density. Then our MCI estimator will be reduced to:

$$
\frac{1}{N} \sum_{i=1}^{N} g\left(\boldsymbol{P}_{i}^{*}\right) q\left(\boldsymbol{P}_{i}^{*}\right)
$$

We shall generate multivariate $t$ vectors of $\boldsymbol{P}_{i}^{*}$ as follows. First, we calculate the OLS estimatec of $\boldsymbol{P}_{i}^{*}, b$, and then the Cholesky decomposition of the covariance matrix such that:

$$
A A^{\prime}=\hat{\sigma}^{2}\left(Z^{*} Z^{*}\right)^{-1}
$$

Then, we generate a $K$-1 vector $\mathbf{z}_{i}$ of independent standard normal random variables, which leads to the $i$-th replication of $\boldsymbol{P}_{i}^{*}$ as $\boldsymbol{P}=b+A \mathbf{z}_{\boldsymbol{i}}$, which is thus drawn from a $(K-1)$ variate normal distribution. We can now convert to a $t$-distributed draw, by generating a $\lambda$ vector $\boldsymbol{w}_{i}$ of independent standard normal variables and calculating $\boldsymbol{P}_{i}^{*}$ as:

$$
\boldsymbol{P}_{i}^{*}=\boldsymbol{b}+A \mathbf{z}_{\boldsymbol{i}}\left(\frac{\lambda}{w_{i}{ }^{\prime} w_{i}}\right)^{\frac{1}{2}}
$$

Thus our parameter estimates can now be obtained using (A4) and $g\left(\boldsymbol{P}_{i}^{*}\right)=\boldsymbol{P}_{i}^{*}$. Similarly we can obtain estimates of higher moments of $P^{*}$ or any other functions of interest. 